agent, is now available. It is the employment of this evidence which is the basis of the present work, and for the manner in which it is presented and analysed, not only the physiologist but all students of medicine will express their gratitude to Prof. Homer Smith.

Since Cushny's time capsular puncture in the frog has been introduced and has made possible a comparison of the glomerular fluid thus obtained with the blood plasma and the urine as it is found in the bladder. Another new, important and fruitful line of investigation has been the study of the secretion of urine by the kidney, of the fish which does not possess a glomerular apparatus but merely tubules. Still another advance has been the study of the excretion of the nonutilizable carbohydrate-insulin-and the comparison of its behaviour in the urine with the normal constituents.

By a careful and very full analysis of all the recent work done along these various lines Prof. Homer Smith concludes that most of the constituents of the urine filter through the glomerulus by a purely physical process and that by a process of absorption, depending on the composition of the plasma, they re-enter the blood in varying amounts and at varying sectors of the tubular apparatus. It would appear, however, that some constituents may pass in the opposite direction from blood to lumen of the tubule. Phenolred, for instance, which in the plasma is bound to the extent of 80 per cent. to protein (which does not filter through the glomerulus) and yet appears abundantly in the urine must do so via the tubules. It is thus seen that the excretion or rather formation of urine is a most complex process and that different elements of the kidney have different functions. It is no doubt because of this fact that in any individual case the various tests of renal efficiency do not necessarily, and as a matter of fact seldom do, indicate the same degree of efficiency. And it would appear that it will be by the correlation of the results of various tests with. the known action of the various renal elements as discussed by Prof. Smith that it may in the future be possible to recognise the particular element of the renal organ which is at fault and thus diseased. In the meantime, however, caution must be exercised in the explanation of urinary phenomena as there still remain many unsolved problems. One might hesitate to apply the findings obtained by work on the frog and the fish to the mammal, and of course operations like capsular puncture are impossible in higher animals, but Prof. Smith has brought together much evidence from the isolated heart-lung-kidney preparation, and from animal experiments; which seem to indicate that similar processes prevail in all animals.

This is a monograph which should be studied by all students of medicine and which will be of the greatest assistance to those workers who desire to further elucidate the important problem of urinary secretion:

\section{MACLEOD'S PHYSIOLOGY IN MODERN MEDICINE. (Eighth Edition.)}

Edited by PhILIP BARD. Henry Kimpton, London. 1938. Price 36/-.

It is gratifying to find that the name of J. J. R. Macleod is to be kept alive by the periodic rejuvenation of his well-known "Physiology in Modern Medicine," a book which has served well many generations of medical students. It is only three years since Macleod himself saw the seventh edition through the press shortly before his untimely death, but during this interval there has been so much advance in our understanding of the fundamentals of physiology, or the institutes of medicine as this branch of science used to be so aptly called, that an up-to-date exposition is called for. In this, the eighth edition, a group of Macleod's devoted and admiring colleagues, headed by Philip Bard, Professor of Physiology at Johns Hopkins University School of Medicine, have collaborated in the work of revision which has necessitated a rewriting of some of the chapters.

Prof. Philip Bard has undertaken the revision of the section dealing with the nervous system, Prof. Olmsted of California that of the special senses, Prof. Bazett of Pennsylvania the part dealing with the circulation. Prof. Schmidt, also of Pennsylvania, has revised the section on respiration, Prof. Cowgill that on the physiology of the alimentary canal, Dr. Gemmill of Johns Hopkins has rewritten the part on metabolism and nutrition, Dr. Hoskins that part devoted to the endocrine glands and Prof. Gregersen those sections dealing with the kidney and water regulation in the body. 
Such a group of authors guarantees a lucid and up-to-date exposition of the above mentioned subjects which form the very basis of modern medicine. In the different chapters the work of recent years is analysed and reviewed and woven into a logical story of the present state of our knowledge with its implication in the study, understanding and treatment of disease.

The book is well produced. The type is clear and pleasing. The text is profusely illustrated with charts and diagrams and pictures (355 in all), and there is a liberal bibliography which is well up-to-date as well as a full and ample index.

\section{THE CONSTRUCTION OF VULCANITE APPLICATORS FOR APPLYING RADIUM TO LESIONS OF THE BUCCAL CAVITY, LIPS ORBIT AND ANTRUM.}

By Desmond Greer WALKer, M.A., M.Dent.Sc., M.B., B.Ch. Foreword by W. WARWICK JAMES, O.B.E., F.R.C.S., L.D.S. John Murray, London. Illustrated with twenty-three plates. Pp. 61. 1938. Price 5s.

The Construction of Vulcanite Applicators for applying Radium to lesions of the Buccal Cavity, Lips, Orbit and Antrum, by Desmond Greer Walker, M.A., M.Dent. Sc., M.B., B.Ch., should prove of great value to radium workers.

It deals concisely with the main physical points in the use of vulcanite applicators and gives full information regarding their construction.

The methods of obtaining impressions and the choice of material is fully discussed and a new method is given in full detail.

The construction of applicators for special cases, and the means of fixation are described in detail.

The book is illustrated by many photographs which are all of good quality.

There is a short list of references.

\section{PRACTICAL PROCEDURES.}

Vol. II. of the Practitioner Handbooks.

Edited by Sir HumpHry Rolleston, Bt.,

and Dr. Alan MONCRIEFF. Eyre and

Spottiswoode, Ltd. 1938. Price 10/6.

This volume consists of reprints of a series of articles on every-day practical procedures in medical practice which were specially written for "The Practitioner" and in which journal they have already appeared. The choice of subjects has been particularly happy as most of the procedures dealt with are liable to be required in daily practice. Some of the procedures are emergency measures, e.g., saline transfusion, blood transfusion, lumbar puncture, thoracocentesis, local anæsthesia and the treatment of poisoning. Thus it is good that the practitioner may have at hand for ready reference practical accounts of the most suitable technique. Other chapters deal with equally important although less urgent therapeutic and diagnostic aids, as e.g., the use of plaster splints, the injection of veins, circumcision, syringing of the ears and the examination of the blood and urine. The format of the book is pleasing, it is light to handle, the type is clear, the diagrams are unusually intelligible and there is a very full index which eminently fits the book for the purpose for which it has been designed.

\section{A TEXTBOOK OF CLINICAL PATHOLOGY.}

Edited by RoY R. KRACKE. Emory Univerşity, Ga. Baillière, Tindall \& Cox. London. Pp. 574. 205 illustrations. 31 plates, 19 in colour. 1938. Price 27/-.

Most physicians appreciate the importance of laboratory work in practical medicine, but find some difficulty in keeping in touch with recent developments and with modern ideas on its scope and limitations. Dr. Kracke has produced a Textbook of Clinical Pathology which helps considerably; lucid, readable, beautifully illustrated, it is written by twelve authorities on the subject for students of medicine and practising physicians.

This is a book which gives just the information a practitioner needs. It is not a book of laboratory technique. Technical details are given, but the authors have wisely confined themselves, as a rule, to one - method only for each investigation; a method chosen for its reliability and simplicity. So much is vital for a complete understanding of the subject.

These accounts of laboratory technique are clear and interesting -an effect achieved in part by numerous excellent illustrations. Students and junior clinical pathologists particularly will find them most valuable; from their point of view there can be no 